\title{
Utilization of the Corncob Agro-Industrial Residue as a Potential Adsorbent in the Biosorption of Bisphenol-A
}

\author{
Jhéssica C. S. Golveia, ${ }^{\circledR a}$ Mariângela F. Santiago, ${ }^{\circledR a}$ Leandro B. Silva, ${ }^{\circledR b}$ \\ Luiza C. Campos ${ }^{\circledR c}$ and Fernando Schimidt ${ }^{\circledR *, d}$ \\ ${ }^{a}$ Faculdade de Farmácia, Universidade Federal de Goiás, 74605-170 Goiânia-GO, Brazil \\ ${ }^{b}$ Furnas Centrais Elétricas SA, 74923-650 Aparecida de Goiânia-GO, Brazil \\ ${ }^{c}$ Department of Civil, Environmental and Geomatic Engineering, University College London, \\ WC1E6BT, London, United Kingdom \\ 'Instituto Federal de Educação, Ciência e Tecnologia de Goiás (IFG), 74055-110 Goiânia-GO, Brazil
}

\begin{abstract}
The presence of plastic waste in water bodies has led to a growing concern due to the impact on human health. Among the most important plastic additive molecules is bisphenol-A (BPA). On the other hand, micro-pollutant removal processes that make use of agro-industrial waste have aroused the interest of researchers. This is because the accumulation of lignocellulosic materials is also an environmental problem. The objective of this work is to use corncob agro-industrial residue (CC) as an adsorbent in the removal of BPA in aqueous matrix. The adsorption studies were carried out in reaction media containing the ground vegetable fiber and BPA solution in concentrations of 10,25 and $50 \mathrm{mg} \mathrm{L}^{-1}$, as well as at $\mathrm{pHs} 3,5,7$ and 9. Isotherms models and kinetic models were evaluated. The results showed that $\mathrm{CC}$ is a potent BPA adsorbent in aqueous solution, leading to about $90 \%$ of removal. The adsorption kinetics followed the pseudo-second order model and isotherm that best suited was the Lagmuir model, and the maximum adsorption capacity was $51.25 \mathrm{mg}$ per gram of adsorbent fiber, after $20 \mathrm{~min}$ of contact. The thermogravimetric analysis allowed us to conclude that $\mathrm{CC}$ is a material resistant to high temperatures, due to the presence of a considerable amount of lignin. Finally, the best results of BPA removal efficiency by $\mathrm{CC}$ compared to activated carbon corroborate its high biosorption capacity.
\end{abstract}

Keywords: biomass, agrowaste, adsorption, microplastics, BPA

\section{Introduction}

The presence of plastic waste in the environment has increased worldwide, and its harmful effects are of great concern, due to its abundance and wide distribution causing impact on health of humans and animals. Not only are plastics a considerable source of pollution, but their additives can be even more harmful to the environment. ${ }^{1}$ Among them, bisphenol-A (BPA) is one of the most used chemical compounds in the world, with approximately 5.5 million tons produced in $2011^{2}$ and more than 100 tons released into the atmosphere. ${ }^{3}$

BPA is a derivative of diphenyl methane and has an irreversible adverse effect on the body, acting on insulin and glucose levels and on thyroid and brain function. It

*e-mail: fernando.quimica@ifg.edu.br is used in the manufacture of different products such as retardants, polycarbonates, protective coatings, adhesives, automotive lenses, paints, construction materials, protective glasses, optical lenses, compact discs, paper coatings, as a developer, in electronic components, composites, resins epoxy and dental sealant, etc. ${ }^{4}$ It is a chemical intermediate (i.e., a monomer), which was first developed as a synthetic estrogen in 1890 and reported as a molecule capable of stimulating the female reproductive system in rats in the $1930 \mathrm{~s}^{2}$ acting as an endocrine disruptor. It is a contaminant of low biodegradability and high resistance to chemical degradation. ${ }^{1}$

The interest in removing BPA from polluted water is growing and the technologies studied include oxidation, ${ }^{5}$ biodegradation, ${ }^{6}$ electrical mineralization, ${ }^{7}$ degradation photocatalytic, ${ }^{8}$ chemical reduction, ${ }^{9}$ adsorption ${ }^{10-12}$ and other processes. Although chemical treatments, especially 
advanced oxidation methods, can break compounds down into simple compounds, these methods are very expensive and ineffective for the removal of recalcitrant compounds. Among the available techniques, adsorption is an efficient technique for removing contaminants from water, due to its several advantages, such as low cost, simple operation and high performance. ${ }^{13}$

The application of highly effective adsorbents is vital to ensure the efficiency of wastewater treatment. Carbonaceous materials such as graphene oxide, ${ }^{14}$ carbon nanotubes, ${ }^{15}$ porous carbon ${ }^{16}$ and activated carbon ${ }^{17}$ have always attracted attention due to its stability as well as the viability of mass production. Activated carbon is one of the most efficient adsorbents, but it has some disadvantages, as it is flammable and difficult to regenerate, which limits its application in the treatment of effluents. Therefore, it is important to look for new adsorbents that have fast adsorption rate, specific surface reactivity and high adsorption capacity.

The use of low-cost ecological materials has been investigated as an alternative in the adsorption process of micropollutants, such as agricultural waste and industrial by-products. Recently, the research focused on the use of natural adsorbents and carbonaceous adsorbents, prepared from natural ones. Regarding the natural adsorbents obtained from agricultural residues, several studies show the possibility of using residual biomass from fruits, plants and cereals. ${ }^{18-34}$

Brazil is the third largest corn producer in the world, with an expected production of almost 96 million tons in 2019, surpassing the 82 million tons harvested in 2018. ${ }^{35}$ Solid residues from corn production such as corncob have great potential for use as a raw material in the production of adsorbents. ${ }^{36}$ Studies show the application of this agroindustrial residue to remove pollutants such as dyes, ${ }^{37,38}$ heavy metals, ${ }^{39}$ polycyclic aromatic hydrocarbons ${ }^{40}$ and ammonia. ${ }^{41,42}$ However, to date, there are no reports of the application of corncob residue to remove plastic compounds such as BPA. The objective of this work is to investigate the removal of the micropollutant BPA from aqueous solution using corn agro-industrial residue as an adsorbent material.

\section{Experimental}

\section{Preparation and treatment of corncrob waste}

Corncob agro-industrial residue (CC) obtained from open markets in Goiânia-GO (Brazil) was dried in an oven with forced air circulation at $40{ }^{\circ} \mathrm{C}$. In order to obtain uniform particles, the dry material was crushed in a knife mill (Nogueira \& Brait Maquinas Ltda, model DMP-Junior, São Paulo, Brazil) and separated in granulometric sieves until 60 mesh particles were obtained. Then, the sieved material was washed thoroughly with distilled water, filtered and dried in an oven at $60^{\circ} \mathrm{C}$ for $24 \mathrm{~h}$.

A chemical treatment of the dried $\mathrm{CC}$ was carried out, with the objective of increasing its adsorption capacity. For this, the agro-industrial waste was exposed to $0.1 \mathrm{~mol} \mathrm{~L}^{-1}$ $\mathrm{HCl}$ (Vetec, Rio de Janeiro, Brazil) for $24 \mathrm{~h}$. Then, the $\mathrm{CC}$ was thoroughly washed with distilled water, until the $\mathrm{pH}$ was close to neutrality (6-7). The powdered corncob particles treated with $\mathrm{HCl}$ were again dried in an oven at $50{ }^{\circ} \mathrm{C}$ for $24 \mathrm{~h}$ and stored in a desiccator until use.

\section{Characterization of the corncob fibers}

Thermogravimetric analysis (TGA) (Shimadzu $60 / 60 \mathrm{H}$, Tokyo, Japan) and the differential scanning calorimetry (DSC) (Shimadzu DSC-60A, Tokyo, Japan) were performed at the Multi-User Analytical Centre of the Chemistry Institute, Federal University of Goiás, following the parameters shown in Table 1.

Table 1. Parameters of the TGA and DSC analyses performed on the CC

\begin{tabular}{lcc}
\hline & TGA & DSC \\
\hline Equipment & DTG 60/60H & DSC-60A \\
Detector & DTG-60H & DSC-60 \\
Atmosphere & nitrogen & nitrogen \\
Flow rate / $\left(\mathrm{mL} \mathrm{min}^{-1}\right)$ & 50 & 50 \\
Cell & platinum & alumina \\
Sample weight / g & 2.127 & 1.603 \\
Sampling time / s & 1 & 1 \\
Temperature rate $/\left({ }^{\circ} \mathrm{C} \mathrm{min}^{-1}\right)$ & 10 & 10 \\
Hold temperature $/{ }^{\circ} \mathrm{C}$ & 650 & 600 \\
\hline
\end{tabular}

TGA: thermogravimetric analysis; DSC: differential scanning calorimetry.

In addition, Fourier transform infrared spectroscopy (FTIR) analysis was performed (PerkinElmer Frontier, Waltham, Massachusetts, USA) with attenuated total reflectance (ATR) sampling. The analysis was performed on in natura untreated CC samples and acid-treated CC samples. The spectra were obtained by the technique of ATR in the medium with infrared range between 650 and $4000 \mathrm{~cm}^{-1}$, resolution of $4 \mathrm{~cm}^{-1}$ and 16 accumulations. Structure and morphological characteristics of the samples were analyzed by scanning electron microscopy (SEM, Tescan, Vega3 XMU, Brun, Czech Republic).

\section{BPA solution}

To evaluate the adsorption capacity of the CC, solutions of BPA (Sigma Chemical Company, St. Louis, MO, USA) dissolved in distilled water were used. The solutions were 
subjected to treatment in an ultrasound bath for $2 \mathrm{~h}$ at $40^{\circ} \mathrm{C}$ for complete dissolution. To quantify the removal efficiency, a calibration curve was constructed. The absorbance was measured at 230 and $277 \mathrm{~nm}$, in a spectrophotometer (SP-2000 UV Meter, Spectrum, Shanghai, China).

\section{Study of the adsorption capacity of CC adsorbent}

The studied parameters were: time of adsorbentadsorbate contact, initial concentration of adsorbate (BPA) and the effect of $\mathrm{pH}$ on adsorption. Quantities of $0.2 \mathrm{~g}$ of $\mathrm{CC}$ were weighted and transferred to $150 \mathrm{~mL}$ Erlenmeyer flasks containing $10 \mathrm{~mL}$ of BPA at concentrations of 50 , 25 and $10 \mathrm{mg} \mathrm{L}^{-1}$. The flasks were subjected to stirring at $150 \mathrm{rpm}$. Samples taken every $10 \mathrm{~min}$ were subjected to vacuum filtration and the absorbance of the supernatants was measured at $230 \mathrm{~nm}$. Negative controls containing only CC and distilled water were performed in order to remove interference from compounds possibly present in the supernatant with absorption at the same maximum absorption wavelength as BPA.

To evaluate the influence of $\mathrm{pH}$ on adsorption, $0.2 \mathrm{~g}$ of CC were added to $150 \mathrm{~mL}$ flasks containing $10 \mathrm{~mL}$ of BPA at a concentration of $10 \mathrm{mg} \mathrm{L}^{-1}$ at different $\mathrm{pH}(3,5$, 7 and 9). For $\mathrm{pH}$ adjustment, solutions of $1 \mathrm{~mol} \mathrm{~L}^{-1} \mathrm{HCl}$ (Vetec, Rio de Janeiro, Brazil) and $1 \mathrm{~mol} \mathrm{~L}^{-1} \mathrm{NaOH}$ (Vetec, Rio de Janeiro, Brazil) were used. The flasks were subjected to agitation at $150 \mathrm{rpm}$ for $5 \mathrm{~min}$. The samples were then filtered and the absorbance of the supernatants was measured at $230 \mathrm{~nm}^{43-45}$

\section{Adsorption kinetics of BPA in CC}

As pseudo-first order and pseudo-second order models are often applied for kinetic analysis of organic compounds, ${ }^{46-49}$ these models were selected in the present study to explain the adsorption kinetics of the CC.

\section{Pseudo-first order kinetics}

The linear shape of the pseudo-first order kinetic model was defined according to equation $1::^{50}$

$\ln (q e-q t)=\ln (q e)-k_{1} t$

where $\mathrm{qt}$ and qe $\left(\mathrm{mg} \mathrm{g}^{-1}\right)$ are the amount of BPA adsorbed per gram of adsorbent at time $t$ and equilibrium, respectively. The $\mathrm{k}_{1}$ is the pseudo-first order kinetic constant $\left(\mathrm{min}^{-1}\right)$. The $\mathrm{k}_{1}$ values were obtained by plotting $\ln (\mathrm{qe}-\mathrm{qt})$ versus $\mathrm{t}$.

\section{Pseudo-second order kinetics}

In the pseudo-second order kinetic model ${ }^{51}$ it is assumed that the adsorption process is controlled by chemical adsorption. For this, equation 2 was used.

$\frac{\mathrm{t}}{\mathrm{qt}}=\frac{1}{\mathrm{k}_{2} \mathrm{qe}^{2}}+\frac{\mathrm{t}}{\mathrm{qe}}$

The $\mathrm{k}_{2}$ (pseudo-second order kinetic constant $\left.\left(\mathrm{g} \mathrm{mg}^{-1} \mathrm{~min}^{-1}\right)\right)$ values were obtained by plotting $\mathrm{t} / \mathrm{qt}$ versus $\mathrm{t}$.

\section{BPA adsorption isotherms in CC}

The adsorption equilibrium isotherms were studied using the Langmuir ${ }^{52}$ and Freundlich ${ }^{53}$ models, which can be expressed by equations 3 to 5 , respectively, where $\mathrm{k}_{\mathrm{F}}\left(\mathrm{mg} \mathrm{g}^{-1}\right)\left(\mathrm{L} \mathrm{mg}^{-1}\right)^{\mathrm{n}}$ and $\mathrm{n}$ are the Freundlich constants related to the adsorption capacity and intensity, respectively, and $\mathrm{k}_{\mathrm{L}}\left(\mathrm{L} \mathrm{mg}^{-1}\right)$ and $\mathrm{q}_{\mathrm{L}}\left(\mathrm{mg} \mathrm{g}^{-1}\right)$ are the Langmuir constants related to the adsorption energy and the maximum adsorption capacity, respectively. ${ }^{54}$

$\frac{1}{q e}=\frac{1}{\left(c_{e} q_{m} k_{L}\right)}+\frac{1}{q_{L}}$

where $c_{e}$ is the concentration of the adsorbate in solution at equilibrium $\left(\mathrm{mg} \mathrm{L}^{-1}\right)$ and $\mathrm{q}_{\mathrm{m}}$ is the amount of material adsorbed per gram of adsorbent $\left(\mathrm{mg} \mathrm{g}^{-1}\right)$.

The adsorption characteristics can be better studied using the equilibrium parameter or the separation factor $R_{L}$ (equation 4 , separation factor equation), where $C_{0}$ is the initial concentration of BPA.

$\mathrm{R}_{\mathrm{L}}=\frac{1}{1+\mathrm{k}_{\mathrm{L}} \mathrm{C}_{0}}$

$\ln (\mathrm{qe})=\ln \left(\mathrm{k}_{\mathrm{F}}\right)+\frac{1}{\mathrm{n}} \ln \left(\mathrm{c}_{\mathrm{e}}\right)$

\section{Comparison of BPA adsorption in CC and activated carbon}

Vegetal activated carbon (Synth, São Paulo, Brazil) was considered a positive control, in order to evaluate the efficiency of CC as an adsorbent compared to a gold standard. The experiment was carried out using $0.2 \mathrm{~g}$ of each adsorbent added to $150 \mathrm{~mL}$ flasks containing $10 \mathrm{~mL}$ of $10 \mathrm{mg} \mathrm{L}^{-1} \mathrm{BPA}$. The entire procedure was performed as described in sub-section "Study of the adsorption capacity of CC adsorbent".

\section{Statistical analysis}

All experimental conditions were performed in triplicate. For analysis of variance in the comparison of 
groups, the analysis of variance (ANOVA) and Tukey's test were applied, in the program BioEstat version 5.0, at the $95 \%$ significance level. ${ }^{55}$

\section{Results and Discussion}

\section{Characterization of the CC}

The TGA results provided quantitative information on the composition of the CC. As shown in Figure 1, there was a slight loss of mass below $100^{\circ} \mathrm{C}$, due to the elimination of water from the plant material. It is observed that the maximum rate of mass loss occurs at a temperature equal to $300^{\circ} \mathrm{C}$. The great thermal stability of the corncob adsorbent is probably due to the presence of lignin, which has a very condensed structure, with the presence of hydroxyls in guaiacyl, syringylic and hydroxyphenolic compounds. ${ }^{56}$ Two stages of decomposition can be clearly observed by analyzing the derivative thermogravimetry (DTG) curve, with maximum loss of mass at 275 and $300{ }^{\circ} \mathrm{C}$. The first peak is characteristic of the decomposition of hemicellulose into monomeric sugars, furans, furfural, aldehydes and acetic acid. The second, at around $300{ }^{\circ} \mathrm{C}$, is characteristic of cellulose degradation, which has greater thermal resistance due to the greater number of inter and intramolecular hydrogen bonds..$^{57}$

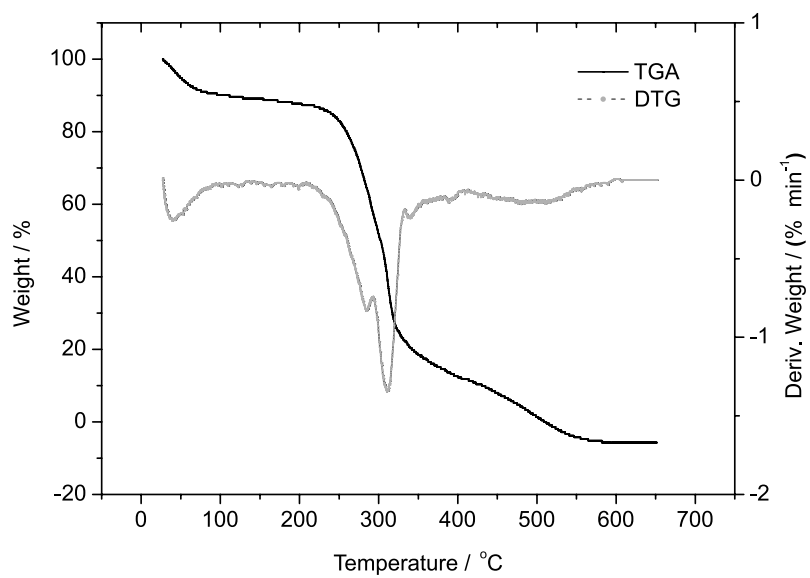

Figure 1. TGA and DTG variation with temperature.

Figure 2 provides information on DSC, showing an exothermic peak that starts at $350^{\circ} \mathrm{C}$ and has its maximum at $450{ }^{\circ} \mathrm{C}$. In 1994 , Bhaduri et al. ${ }^{58}$ found that an exothermic peak with a maximum of $400{ }^{\circ} \mathrm{C}$ was due to the degradation of lignin in a jute sample.

With respect to the FTIR result, Figure 3 shows the spectra obtained for in natura CC fiber (black line) and for $\mathrm{CC}$ fiber treated with $\mathrm{HCl}$ (red line). It is possible to identify a broadband in the $3700-3000 \mathrm{~cm}^{-1}$ region,

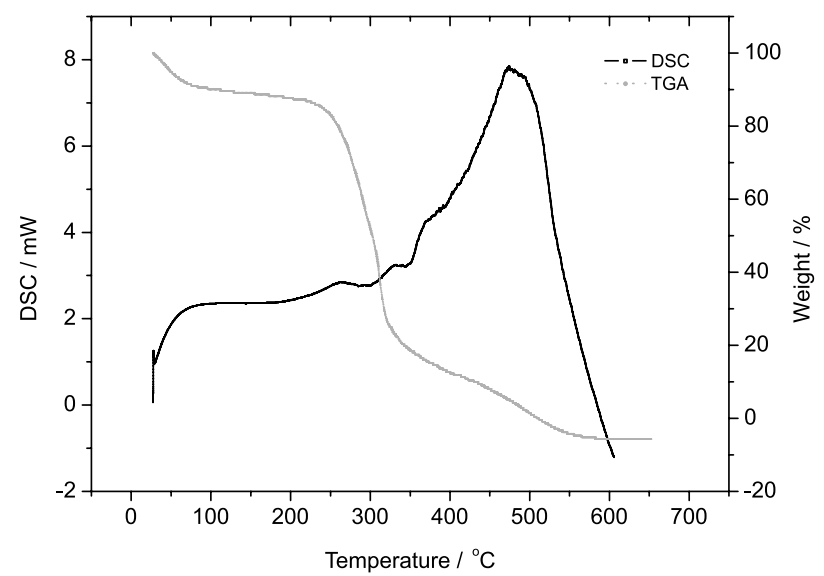

Figure 2. DSC and TGA variation with temperature.

which is usually attributed to a characteristic $\mathrm{O}-\mathrm{H}$ stretch of natural fibers. With the acid treatment of the fiber, an intensification of this band was observed (red line), probably due to the presence of a greater amount of hydroxyl groups. The region ranging from $1100-850 \mathrm{~cm}^{-1}$ corresponds to a characteristic band of $\mathrm{C}-\mathrm{O}-\mathrm{C}$ bonds outside the plane, which may be the $\beta$-(1-4)-glycosidic bonds, present in cellulose. ${ }^{59}$

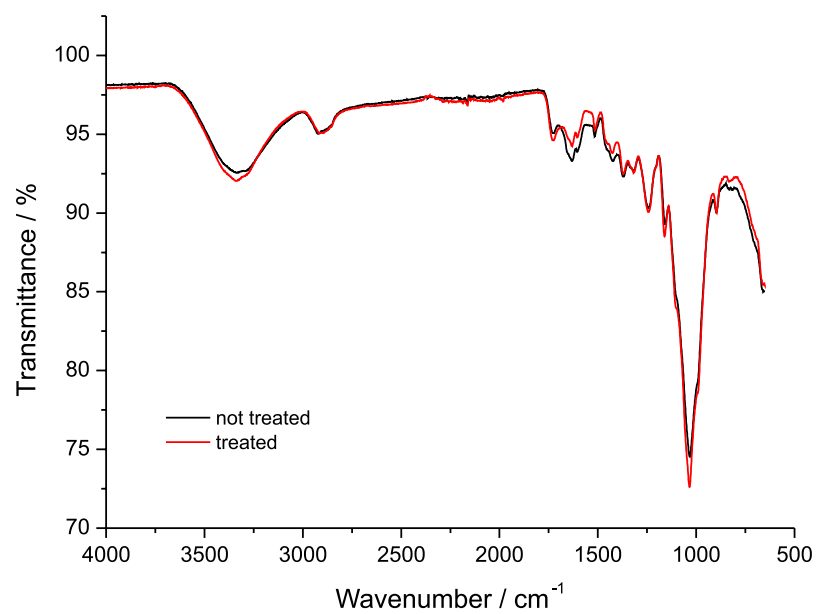

Figure 3. FTIR (ATR) spectra for in natura (black line) and acid-treated fiber of CC (red line).

In the fiber samples analyzed by SEM, the prevalence of micropores was verified (Figure 4). The results are as reported by Sonawanea and Shrivastava ${ }^{60}$ who prepared the fiber by washing with distilled water and selected particle size between 60 and 40 mesh. In this work 60 mesh was used. SEM analysis also showed that after chemical treatment the fiber surface became more corroded, as reported by Ioannidou et al. ${ }^{61}$ The treatment by acid exposed the pores (Figure 4b), a potentially beneficial effect for the use of adsorption of substances in aqueous solution. 

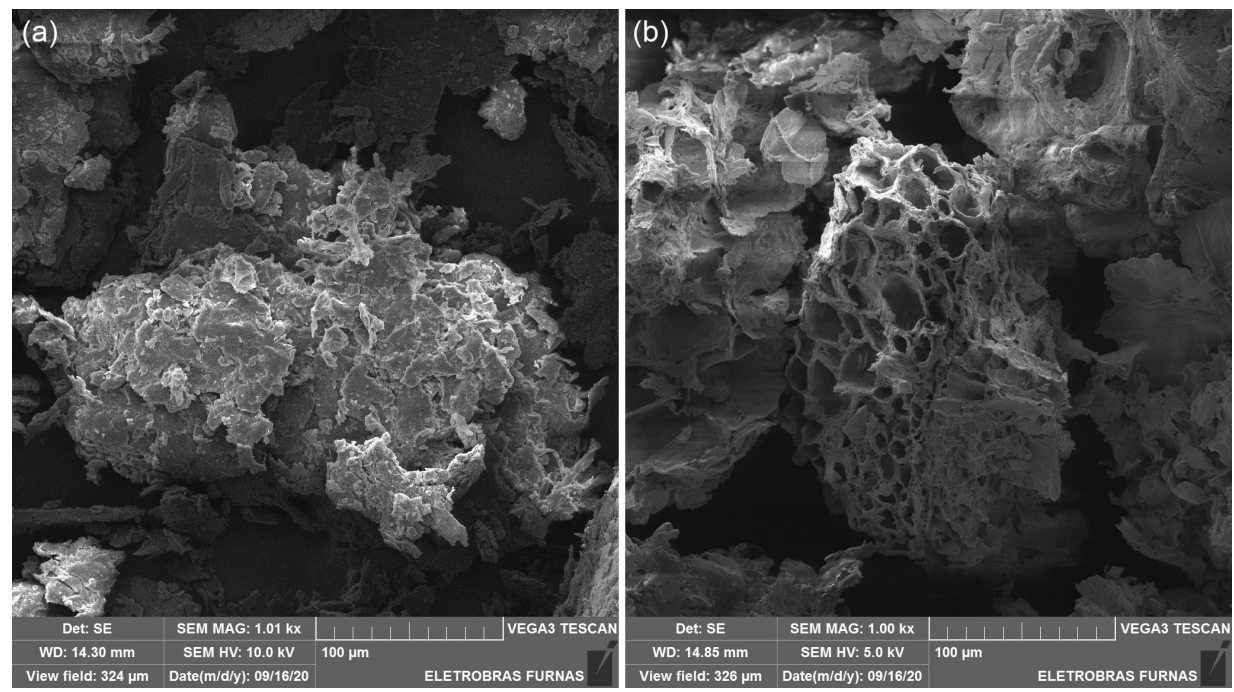

Figure 4. Scanning electron microscopy (SEM) images for CC in natura (a) and CC treated with acid (b).

\section{Effect of contact time and initial BPA concentration}

The effect of contact time on the efficiency of BPA removal in aqueous solution was investigated every $10 \mathrm{~min}$, until the final time of $70 \mathrm{~min}$ at neutral $\mathrm{pH}$ at concentrations of 10,25 and $50 \mathrm{mg} \mathrm{L}^{-1}$. Figure 5 shows the increase in the removal efficiency up to $20 \mathrm{~min}$, after which there was a tendency towards a steady state. The best removal efficiency at the beginning of the process was due to the availability of a high number of sites available for adsorption. Over time, the available sites decrease, until balance.

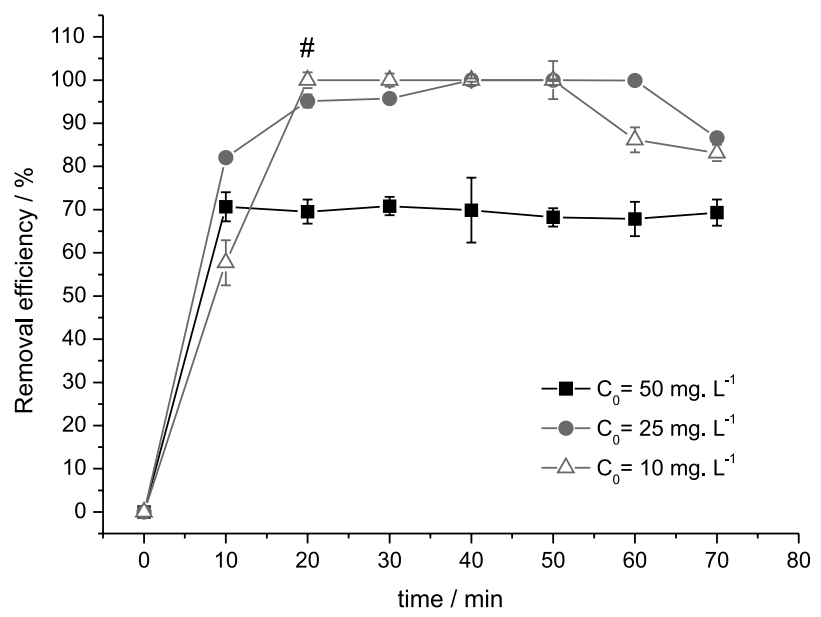

Figure 5. Effect of contact time and initial concentration of BPA on adsorption (amount of adsorbent: $0.2 \mathrm{~g} ; \mathrm{pH}=7$; agitation of $150 \mathrm{rpm}$ ). The symbol \# represents a statistically significant difference when the removal efficiency was compared to concentrations of 10 and $25 \mathrm{mg} \mathrm{L}^{-1}$ at time $\mathrm{T}_{20}(p<0.01$ in the Tukey's test)

Regarding the initial concentration of BPA, it was observed that the removal efficiency decreased with increasing initial amount of adsorbate. Therefore, it is clear that the removal efficiency depends on the concentration of BPA at the beginning of the process.

At time $20 \mathrm{~min}$, it was observed that the initial concentration of $10 \mathrm{mg} \mathrm{L}^{-1}$ led to the greatest removal efficiency of the phenolic compound BPA. When performing the statistical comparison between the initial concentrations at time $20 \mathrm{~min}$, a significant difference was obtained between the three conditions, with $p<0.01$ in the Tukey's test. Therefore, in the following experiments, the initial concentration of $10 \mathrm{mg} \mathrm{L}^{-1}$ was used.

The equilibrium time achieved after $20 \mathrm{~min}$ is less than the equilibrium time reported in other studies that used alternative material in the adsorption of micropollutants. Dehghani et al. ${ }^{47}$ used chitosan to adsorb BPA. The authors found that the removal efficiency was maximum after $75 \mathrm{~min}$. In a study by Silva et al. ${ }^{26}$ the removal of the dye Blue Bright 2BE from aqueous matrix by sugarcane bagasse took $12 \mathrm{~h}$ until the adsorption equilibrium. Palma et al..$^{30}$ also aimed to remove dye, and reached maximum adsorption in 65 min when using avocado residue as an adsorbent material.

\section{Influence of $\mathrm{pH}$ on adsorption}

The effect of $\mathrm{pH}$ on BPA adsorption into corncob fiber was evaluated, in the amount of $0.2 \mathrm{~g}$ of vegetable fiber for an initial concentration of $10 \mathrm{mg} \mathrm{L}^{-1}$ and the removal efficiency was evaluated after $5 \mathrm{~min}$. Figure 6 shows the removal results at $\mathrm{pH} 3,5,7$ and 9. It is observed that the removal efficiency is higher at acidic $\mathrm{pH}$. However, there was no statistically significant difference between the removals obtained at $\mathrm{pH} 3,5$ and 7 . In $\mathrm{pH} 9$, the efficiency of the adsorption process is significantly lower.

The best removal efficiency at acid to neutral $\mathrm{pH}$ is due to the fact that the chemical structure of BPA is anionic. ${ }^{47}$ 


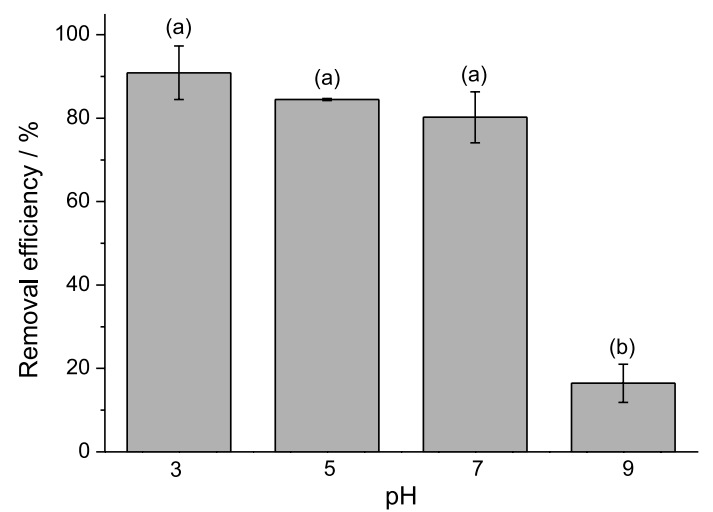

Figure 6. Effect of pH on BPA adsorption (amount of adsorbent: $0.2 \mathrm{~g}$; $\mathrm{pH}=3,5,7$ and 9; agitation of $150 \mathrm{rpm}$ ). Different letters mean a statistically significant difference when comparing the removal efficiency at different $\mathrm{pH}(p<0.01$ in the Tukey's test).

The surface charge of BPA is negative at $\mathrm{pH}$ greater than 5 . Thus, in alkaline media, the number of negative charges increases while the electrostatic attraction force between the adsorbent and the contaminant decreases. The $\mathrm{OH}^{-}$ions compete with BPA phenolic molecules to obtain adsorption sites, which explains the low efficiency at $\mathrm{pH}$ 9. This result is in line with that obtained by Dehghani et al..$^{47}$ and Hamdaoui and Naffrechoux. ${ }^{62}$

\section{Adsorption kinetics}

The adsorption kinetics of BPA in CC was investigated using the pseudo-first order and pseudo-second order models. The calculated parameters are found in Table 2. The results indicate that the adsorption preferably follows a pseudo-second order kinetics, due to the better correlation coefficient $R^{2}(0.9636$ in relation to 0.8677$)$. Figures 7 and 8 show the pseudo-first order and pseudo-second order kinetics curves.

Table 2. Kinetic parameters for BPA adsorption in CC

\begin{tabular}{lcc}
\hline & Pseudo-first order & Pseudo-second order \\
\hline $\mathrm{qe}, \exp /\left(\mathrm{mg} \mathrm{g}^{-1}\right)$ & 51.25 & 51.25 \\
$\mathrm{k}$ & $0.036 \mathrm{~min}^{-1}$ & $0.0164 \mathrm{~g} \mathrm{mg}^{-1} \mathrm{~min}^{-1}$ \\
$\mathrm{R}^{2}$ & 0.8677 & 0.9636 \\
\hline
\end{tabular}

qe, exp: experimental value of the amount of bisphenol-A (BPA) adsorbed per gram of absorbent at equilibrium; $\mathrm{k}$ : kinetic constant; $\mathrm{R}^{2}$ : correlation coefficient.

BPA adsorption studies carried out by Koduru et al. ${ }^{63}$ Arampatzidou et al. ${ }^{64}$ and Zbair et al ${ }^{65}$ also added better kinetic adjustments using the pseudo-second order model. According to Ruthven, ${ }^{66}$ the pseudo-second order kinetics concerns the chemical adsorption process and is highly specific, involving the exchange of electrons between adsorbent and adsorbate. The BPA molecules are attracted

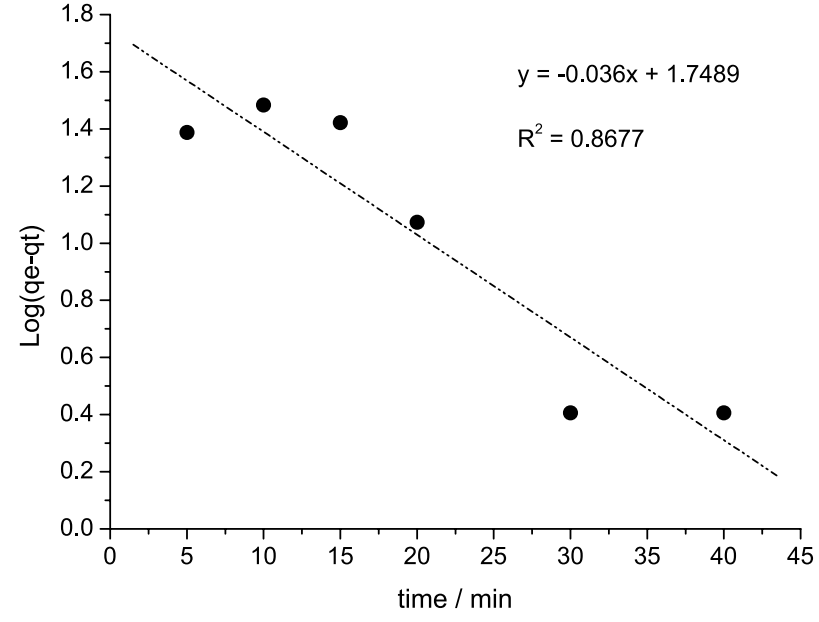

Figure 7. Linearization of the pseudo-first order kinetic model for BPA adsorption in $\mathrm{CC}$ waste.

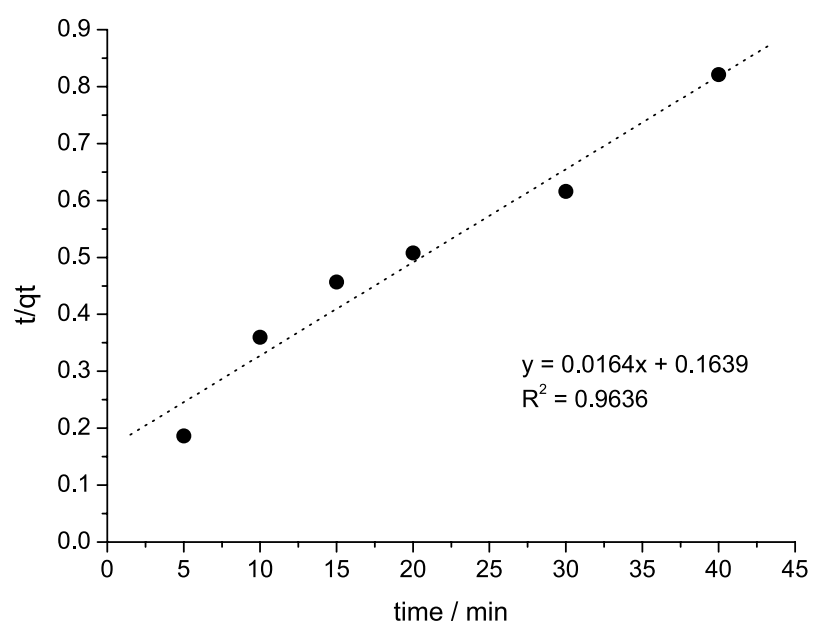

Figure 8. Linearization of the pseudo-second order kinetic model for BPA adsorption in CC waste.

to active centers with the formation of an adsorbate monolayer. This process is susceptible to dissociation, so can occur in a wide range of concentrations.

\section{Adsorption isotherms}

The behavior of BPA adsorption onto corncob fiber was analyzed using the Freundlich ${ }^{53}$ and Langmuir ${ }^{52}$ isotherm models. The calculated parameters are listed in Table 3, which shows the correlation coefficient values of 0.9911 and 0.9978 for the Freundlich and Langmuir models, respectively. The higher value obtained for the Langmuir isotherm implies that the experiments were better suited to this model. Additionally, the graphs corresponding to the BPA isotherm in CC, an adjustment curve to the Langmuir and Freundlich models are shown in Figures 9, 10 and 11, respectively.

In general, a favorable adsorption tends to have a value of $\mathrm{n}$ between 1 and $10 .{ }^{67}$ The value of $\mathrm{n}$ shown in 
Table 3. Constants of the Freundlich and Langmuir isotherm models

\begin{tabular}{lcc}
\hline & $\mathrm{n}$ & 1.695 \\
Freundlich & $1 / \mathrm{n}$ & 0.5901 \\
& $\mathrm{k}_{\mathrm{F}} /\left(\mathrm{mg} \mathrm{g}^{-1}\right)\left(\mathrm{L} \mathrm{mg}^{-1}\right)^{\mathrm{n}}$ & 37.77 \\
& $\mathrm{R}^{2}$ & 0.9911 \\
\hline \multirow{3}{*}{ Langmuir } & $\mathrm{k}_{\mathrm{L}} /\left(\mathrm{L} \mathrm{mg}^{-1}\right)$ & 4.46 \\
& $\mathrm{q}_{\mathrm{L}} /\left(\mathrm{mg} \mathrm{g}^{-1}\right)$ & 49.75 \\
& $\mathrm{R}_{\mathrm{L}}$ & 0.0022 \\
& $\mathrm{R}^{2}$ & 0.9978 \\
\hline
\end{tabular}

$\mathrm{n}$ : Freundlich constant related to intensity; $\mathrm{k}_{\mathrm{F}}$ : Freundlich constant related to the adsorption capacity; $\mathrm{R}^{2}$ : correlation coefficient; $\mathrm{k}_{\mathrm{L}}$ : Langmuir constant related to the adsorption energy; $\mathrm{q}_{\mathrm{L}}$ : Langmuir constant related to maximum adsorption capacity; $\mathrm{R}_{\mathrm{L}}$ : separation factor.

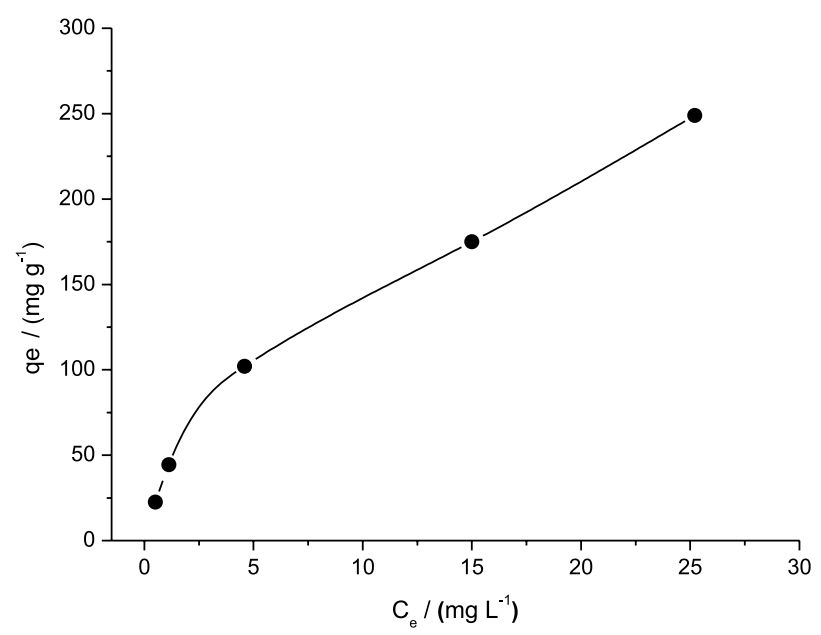

Figure 9. BPA adsorption isotherm in CC.

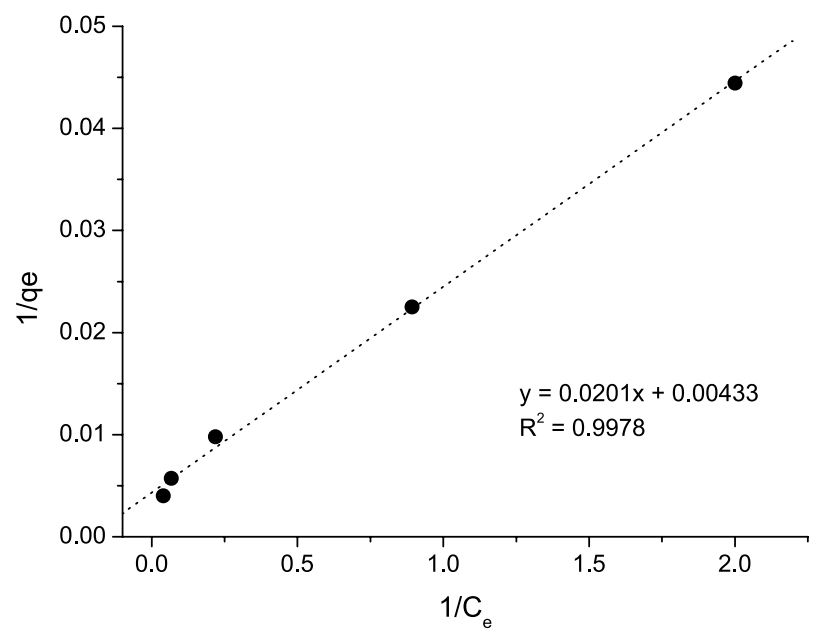

Figure 10. Linear adjustment of BPA adsorption in $\mathrm{CC}$ according to the Langmuir model.

Table 3 was greater than 1 , indicating that the adsorption is favorable. These data coincide with the $\mathrm{R}_{\mathrm{L}}$ values, and in most situations of adsorption, the adsorbate prefers the solid to the liquid phase and the adsorption is said to be favorable when $0<\mathrm{R}_{\mathrm{L}}<1 .{ }^{67} \mathrm{With}$ respect to the calculated

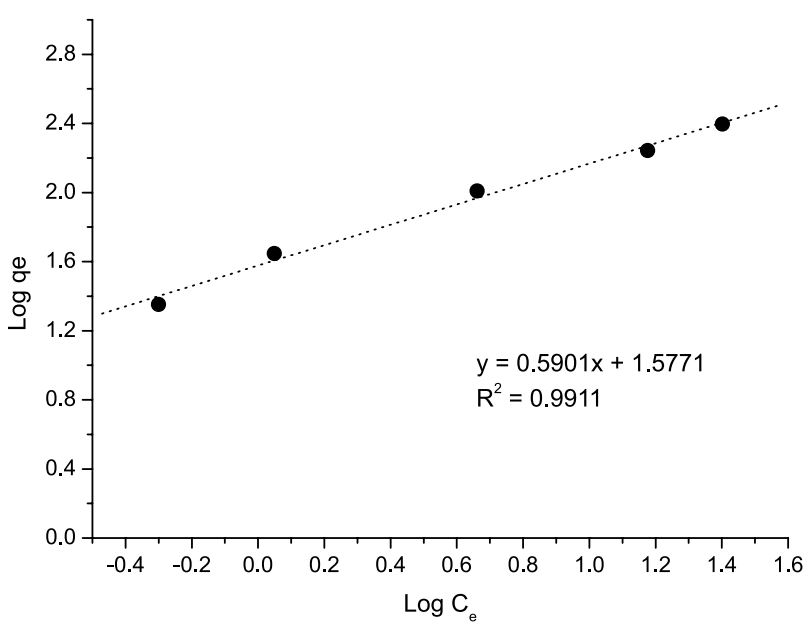

Figure 11. Linear adjustment of BPA adsorption in $\mathrm{CC}$ according to the Freundlich model.

$\mathrm{q}_{\mathrm{L}}$ value, which was $49.75 \mathrm{mg} \mathrm{g}^{-1}$, it was observed that this value was close to that obtained experimentally, of $51.25 \mathrm{mg} \mathrm{g}^{-1}$. The proximity of the values obtained theoretically and experimentally corroborates the best fit to the Langmuir model.

The value of maximum adsorption capacity obtained in this work is relevant, when compared to those obtained in other studies that used adsorbent material for BPA removal. Table 4 shows the maximum BPA adsorption values obtained with different adsorbent materials, for studies that used plant and synthetic materials. Chang et al. ${ }^{68}$ reached $181.8 \mathrm{mg} \mathrm{g}^{-1}$, but the plant material underwent a thermal process to form activated carbon. The use of fresh plant material as an adsorbent is advantageous, since it does not require the carbonization process. It is important to note that the corncob agroindustrial residue has only undergone chemical treatment in order to enhance its adsorptivity.

Table 4. Maximum BPA adsorption values

\begin{tabular}{|c|c|c|}
\hline Adsorbent & $\mathrm{q}_{\max } /\left(\mathrm{mg} \mathrm{g}^{-1}\right)$ & Reference \\
\hline Porous carbon from bamboo & 41.8 & Asada et al..$^{16}$ \\
\hline $\begin{array}{l}\text { Activated carbon from rice straw } \\
\text { agricultural waste }\end{array}$ & 181.8 & Chang et al. ${ }^{68}$ \\
\hline Ray fibric peat & 15.97 & Zhou et al. ${ }^{69}$ \\
\hline Clay & 151.52 & Zheng et al. ${ }^{70}$ \\
\hline Commercial chitosan & 27.02 & Dehghani et al..$^{47}$ \\
\hline Barkley husk & 15.51 & Balarak $^{48}$ \\
\hline Rice husk ash & 8.72 & Sudhakar et al..$^{71}$ \\
\hline Graphene & 94.06 & Bele et al. ${ }^{46}$ \\
\hline$\beta$-Cyclodextrin-functionalized & 52.7 & Lee and $\mathrm{Kwak}^{72}$ \\
\hline$\gamma-\mathrm{Fe}_{2} \mathrm{O}_{3} /$ bentonite modified & 77.36 & Cao et al..$^{49}$ \\
\hline Corncob agro-industrial waste & 51.25 & present study \\
\hline
\end{tabular}

$\mathrm{q}_{\max }$ : maximum adsorption capacity. 
Comparison of BPA adsorption onto CC and activated carbon

As shown in Figure 12, CC proved to be an adsorbent as effective as activated carbon, after 20 min of contact. It was observed that in the first $10 \mathrm{~min}$, activated carbon had a better ability to adsorb BPA, but after 20 min of contact, there was no difference in the removal efficiencies of the two materials. It is worth mentioning that our corncob fibers have only undergone chemical treatment and not been thermal activated.

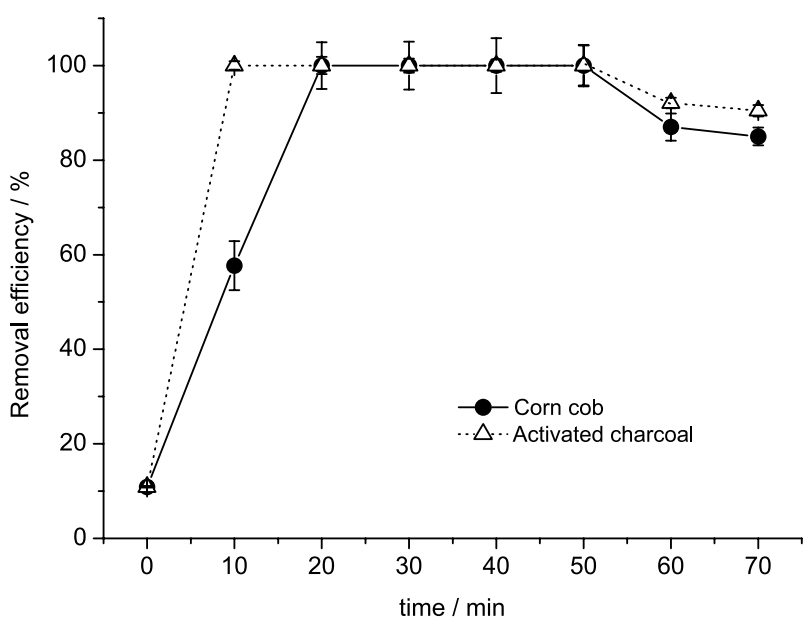

Figure 12. Variation of BPA removal efficiency by $\mathrm{CC}$ and activated carbon with contact time.

\section{Conclusions}

The results obtained in this study revealed that the adsorption of BPA in CC is fast and potent. The removal efficiency values (>90\%) obtained are higher than those achieved in other studies that used different materials in the adsorption of BPA. The fact that $\mathrm{CC}$ is resistant to high temperatures, and the fact that the biosorption reaction took place over a wide $\mathrm{pH}$ range ( 3 to 7 ), makes $\mathrm{CC}$ residue interesting for applications in various $\mathrm{pH}$ and temperature conditions. In addition, because the removal efficiency is comparable to the gold standard means that this biomaterial has the potential to be used as a substitute for activated carbon in large-scale adsorption processes. In this way, several environmental problems could be minimized, including the accumulation of agro-industrial waste and the presence of plastic compounds such BPA in water bodies.

\section{Acknowledgments}

This work was funded by CAPES/Brazil and CNPq/ Brazil. The authors are grateful to Eletrobras Furnas for the scanning electron microscopy (SEM) images.

\section{References}

1. Acosta, R.; Nabarlatz, D.; Sánchez-Sánchez, A.; Jagiello, J.; Gadonneix, P.; Celzard, A.; Fierro, V.; J. Environ. Chem. Eng. 2018, 6, 823 .

2. Rochester, J. R.; Reprod. Toxicol. 2013, 42, 132.

3. Vandenberg, L. N.; Maffini, M. V.; Sonnenschein, C.; Rubin, B. S.; Soto, A. M.; Endocr. Rev. 2009, 30, 75.

4. Batra, S.; Datta, D.; Sai Beesabathuni, N.; Kanjolia, N.; Saha, S.; Process Saf. Environ. Prot. 2018, 122, 232.

5. Ahmed, M. M.; Barbati, S.; Doumenq, P.; Chiron, S.; Chem. Eng. J. 2012, 197, 440.

6. Huang, M.; Tian, S.; Chen, D.; Zhang, W.; Wu, J.; Chen, L.; J. Environ. Sci. 2012, 24, 1594.

7. Lin, H.; Niu, J.; Xu, J.; Li, Y.; Pan, Y.; Electrochim. Acta 2013, 97, 167.

8. Xu, L.; Wang, G.; Ma, F.; Zhao, Y.; Lu, N.; Guo, Y.; Yang, X.; Appl. Surf. Sci. 2012, 258, 7039.

9. Islam, M. T.; Dominguez, N.; Ahsan, M. A.; DominguezCisneros, H.; Zuniga, P.; Alvarez, P. J.; Noveron, J. C.; J. Environ. Chem. Eng. 2017, 5, 4185.

10. Kim, Y. H.; Lee, B.; Choo, K. H.; Choi, S. J.; Microporous Mesoporous Mater. 2011, 138, 184.

11. Hyder, A. H. M. G.; Begum, S. A.; Egiebor, N. O.; J. Environ. Chem. Eng. 2015, 3, 1329.

12. Islam, M. T.; Hernandez, C.; Ahsan, M. A.; Pardo, A.; Wang, H.; Noveron, J. C.; J. Environ. Chem. Eng. 2017, 5, 5270.

13. Kyzas, G. Z.; Kostoglou, M.; Lazaridis, N. K.; Lambropoulou, D. A.; Bikiaris, D. N.; Chem. Eng. J. 2013, 222, 248.

14. Gao, Y.; Li, Y.; Zhang, L.; Huang, H.; Hu, J.; Shah, S. M.; Su, X.; J. Colloid Interface Sci. 2012, 368, 540.

15. Kuo, C. Y.; Desalination 2009, 249, 976.

16. Asada, T.; Oikawa, K.; Kawata, K.; Ishihara, S.; Iyobe, T.; Yamada, A.; J. Health Sci. 2004, 50, 588.

17. Bautista-Toledo, I.; Ferro-Garcia, M. A.; Rivera-Utrilla, J.; Moreno-Castilla, C.; Vegas Fernandez, F. J.; Environ. Sci. Technol. 2005, 39, 6246.

18. Contreras, E.; Sepulveda, L.; Palma, C.; Int. J. Chem. Eng. 2012, 679, 352.

19. Sepúlveda, L. A.; Cuevas, F. A.; Contreras, E. G.; Environ. Technol. 2015, 36, 1913.

20. Elizalde-González, M. P.; Mattusch, J.; Peláez-Cid, A. A.; Wennrich, R.; J. Anal. Appl. Pyrolysis 2007, 78, 185.

21. Elizalde-González, M. P.; Hernández-Montoya, V.; Int. J. Chem. Eng. 2008, 1, 243.

22. Franca, A. S.; Oliveira, L. S.; Ferreira, M. E.; Desalination 2009, 249, 267.

23. Hameed, B. H.; Mahmoud, D. K.; Ahmad, A. L.; J. Hazard. Mater. 2008, 158, 65.

24. Patil, S.; Renukdas, S.; Patel, N.; Int. J. Environ. Sci. 2011, 1, 711. 
25. Cherifi, H.; Hanini, S.; Bentahar, F.; Desalination 2009, 244, 177.

26. Silva, L. G. D.; Ruggiero, R.; Gontijo, P. M.; Pinto, R. B.; Royer, B.; Lima, E. C.; Fernandes, T. H. M.; Calvete, T.; Chem. Eng. J. 2011, 168, 620 .

27. Cherifi, H.; Fatiha, B.; Salah, H.; Appl. Surf. Sci. 2013, 282, 52.

28. Pezoti, O.; Cazetta, A. L.; Souza, I. P. A. F.; Bedin, K.; Martins, A. C.; Silva, T.; Almeida, V. H. C.; J. Ind. Eng. Chem. 2014, $20,4401$.

29. Cara, I. G.; Trinca, L. C.; Trofin, A.; Cazacu, A.; Topa, D.; Peptu, C. A.; Jitareanu, G.; Appl. Surf. Sci. 2015, 358, 586.

30. Palma, C.; Lloret, L.; Puen, A.; Tobar, M.; Contreras, E.; Chin. J. Chem. Eng. 2016, 24, 521.

31. Tahir, H.; Sultan, M.; Akhtar, N.; Hameed, U.; Abid, T.; J. Saudi Chem. Soc. 2016, 20, S115.

32. Beltrame, K. K.; Cazetta, A. L.; Souza, P. S. C.; Spessato, L.; Silva, T. L.; Almeida, V. C.; Ecotoxicol. Environ. Saf. 2018, 147, 64 .

33. Brito, M. J. P.; Veloso, C. M.; Santos, L. S.; Bonomo, R. C. F.; Fontan, I. R. C.; Powder Technol. 2018, 339, 334.

34. Pirozzi, C.; Pontoni, L.; Fabbricino, M.; Bogush, A.; Campos, L. C.; J. Cleaner Prod. 2020, 244, 118675.

35. Companhia Nacional de Abastecimento (CONAB); https://www. conab.gov.br/info-agro/safras/graos, accessed in March 2021.

36. Bagheri, N.; Abedi, J.; Chem. Eng. Res. Des. 2011, 89, 2038.

37. Preethi, S.; Sivasamy, A.; Sivanesan, S.; Ramamurthi, V.; Swaminathan, G.; Ind. Eng. Chem. Res. 2006, 45, 7627.

38. Berber-Villamar, N. K.; Netzahuatl-Muñoz, A. R.; MoralesBarrera, L.; Chávez-Camarillo, G. M.; Flores-Ortiz, C. M.; Cristiani-Urbina, E.; PloS One 2018, e0196428.

39. Shim, J.; Lim, J. M.; Shea, P. J.; Oh, B. T.; J. Hazard. Mater. 2014, 272, 129.

40. Li, X.; Dongli, T.; Allison, G.; Chunyun, J.; Bull Environ. Contam. Toxicol. 2016, 96, 113.

41. Vu, T. M.; Trinh, V. T.; Doan, D. P.; Van, H. T.; Nguyen, T. V.; Vigneswaran, S.; Ngo, H. H.; Sci. Total Environ. 2017, 579, 612 .

42. Vu, M. T.; Chao, H. P.; Trinh, T. V.; Le, T. T.; Lin, C. C.; Trane, H. N.; J. Cleaner Prod. 2018, 180, 560.

43. Aurand, C.; Rapid Determination of Packaging Contaminants in Food and Beverages, Supelco Analytical Reporter, vol. 30.1; Sigma-Aldrich: St. Louis, MO, USA, 2012, p. 8, available at https://www.sigmaaldrich.com/content/dam/sigma-aldrich/ docs/Supelco/The_Reporter/1/reporter_51.pdf, accessed in March 2021.

44. Cao, G.; Zhuang, Y.; Liu, B.; S. Afr. J. Chem. 2014, 67, 99.

45. Aristiawan, Y.; Aryana, N.; Putri, D.; Styarini, D.; Procedia Chem. 2015, 16, 202.

46. Bele, S.; Samanidou, V.; Deliyanni, E.; Chem. Eng. Res. Des. 2016, 109, 573.

47. Dehghani, M. H.; Ghadermazi, M.; Bhatnagar, A.; Sadighara, P.;
Jahed-Khaniki, G.; Heibati, B.; McKay, G.; J. Environ. Chem. Eng. 2016, 4, 2647.

48. Balarak, D.; Int. J. ChemTech. Res. 2016, 9, 681.

49. Cao, Y.; Zhou, G.; Zhou, R.; Wang, C.; Chi, B.; Wang, Y.; Hua, C.; Qiu, J.; Jin, Y.; Wu, S.; Sci. Total Environ. 2020, 708, 134669.

50. Ho, Y. S.; Mckay, G.; Water Res. 2000, 34, 735.

51. Ho, Y. S.; McKay, G.; Process Biochem. 1999, 34, 451.

52. Langmuir, I.; J. Am. Chem. Soc. 1916, 2221.

53. Freundlich, H.; Z. Phys. Chem. 1906, 57, 385.

54. Weber, W. J.; McGinley, P.; Katz, L.; Water Res. 1991, 25, 499.

55. Silva, A. C. S.; Veiga, J. B.; Veiga, B. B.; Caioni, C.; Oliveira, A. S.; Rev. Univ. Vale Rio Verde 2014, 12, 375, available at http://periodicos.unincor.br/index.php/revistaunincor/article/ view/1485, accessed in March 2021.

56. Martin, A. R.; Martins, M. A.; Silva, O. R. R. F.; Mattoso, L. H. C.; Thermochim. Acta 2010, 506, 14.

57. Peng, P.; Peng, F.; Bian, J.; Xu, F.; Sun, R. C.; Kennedy, J. F.; Carbohydr. Polym. 2011, 86, 883.

58. Bhaduri, S. K.; Mathew, M. D.; Day, A.; Pandey, S.; Cellul. Chem. Technol. 1994, 28, 391.

59. Nikonenko, N. A.; Buslov, D. K.; Sushko, N. I.; Zhbankov, R. G.; Biopolymers 2000, 57, 257.

60. Sonawanea, G. H.; Shrivastava, V. S.; Desalination 2009, 247, 430.

61. Ioannidou, O. A.; Zabaniotou, A. A.; Stavropoulos, G. G.; Islam, M. A.; Albanis, T. A.; Chemosphere 2010, 80, 1328.

62. Hamdaoui, O.; Naffrechoux, E.; J. Hazard. Mater. 2007, 147, 401.

63. Koduru, R. J.; Lingamdinne, P. L.; Singh, J.; Choo, K.; Process Saf. Environ. Prot. 2016, 103, 87.

64. Arampatzidou, A. C.; Voutsa, D.; Deliyanni, E. A.; Matis, K. A.; Desalin. Water Treat. 2017, 76, 232.

65. Zbair, M.; Ainassaari, K.; Drif, A.; Ojala, S.; Bottlinger, M.; Pirilä, M.; Keiski, R. L.; Bensitel, M.; Brahmi, R.; Environ. Sci. Pollut. Res. 2017, 25, 1869.

66. Ruthven, D. M.; Principles of Adsorption and Adsorption Processes; John Wiley \& Sons: New York, USA, 1984.

67. Cooney, D. O.; Adsorption Design for Wastewater Treatment; CRC Press: Florida, USA, 1999.

68. Chang, K. L.; Hsieh, J. F.; Ou, B. M.; Chang, M. H.; Hseih, W. Y.; Lin, J. H.; Huang, P. J.; Wong, K. F.; Chen, S. T.; Sep. Sci. Technol. 2012, 47, 1514.

69. Zhou, Y.; Lu, P.; Lu, J.; Carbohydr. Polym. 2012, 88, 502.

70. Zheng, S.; Sun, Z.; Park, Y.; Ayoko, G. A.; Frost, R. L.; Chem. Eng. J. 2013, 234, 416.

71. Sudhakar, P.; Mall, I. D.; Srivastava, V. C.; Desalin. Water Treat. 2016, 57, 12375.

72. Lee, J. H.; Kwak, S. Y.; Appl. Surf. Sci. 2019, 467, 178.

Submitted: November 27, 2020

Published online: March 22, 2021 